\title{
Endangered Wildlife Conservation Enhances Regional Economic Development: A Case Study of Tibetan Macaque (Macaca thibetana) and Fuxi Village in Mount Huangshan, China
}

\author{
Ruoyu Wang1*, Linkun Ma1, Zirui Wang1, Dongpo Xia ${ }^{2,3}$, Longzhu Li ${ }^{4}$ \\ ${ }^{1}$ International Department, Hefei No. 8 High School, Hefei, China \\ ${ }^{2}$ School of Life Sciences, Anhui University, Hefei, China \\ ${ }^{3}$ International Collaborative Research Center for Huangshan Biodiversity and Tibetan Macaque Behavioral Ecology, Hefei, China \\ ${ }^{4}$ Biology Teaching and Research Group, Hefei No. 8 High School, Hefei, China \\ Email: ^2253235120@qq.com
}

How to cite this paper: Wang, R.Y., Ma, L.K., Wang, Z.R., Xia, D.P. and Li, L.Z. (2021) Endangered Wildlife Conservation Enhances Regional Economic Development: A Case Study of Tibetan Macaque (Macaca thibetana) and Fuxi Village in Mount Huangshan, China. Open Journal of Ecology, 11, 635-644. https://doi.org/10.4236/oje.2021.119040

Received: August 4, 2021

Accepted: September 3, 2021

Published: September 6, 2021

Copyright $\odot 2021$ by author(s) and Scientific Research Publishing Inc. This work is licensed under the Creative Commons Attribution International License (CC BY 4.0). http://creativecommons.org/licenses/by/4.0/

\begin{abstract}
The economic development of key biodiversity conservation areas and their conservation measures are underpinned by a mutually complementary and synergistic development model. Regional economic development depends on conservation awareness in biodiversity conservation areas. Moreover, the effectiveness of biodiversity conservation can be indicated by endangered wildlife conservation. This study investigated the current conservation of Huangshan Tibetan macaque (Macaca thibetana) - an endemic endangered species in the Mount Huangshan Scenic Area located in a biodiversity conservation hotspot in China, the conservation awareness of residents and visitors, and changes in local economic income through field survey. It provides inspiration and a characteristic demonstration to build a synergistic model of endangered wildlife conservation, biodiversity maintenance, and sustainable regional economic development.
\end{abstract}

\section{Keywords}

Biodiversity, Huangshan Tibetan Macaque, Regional Economy, Ecosystem Services

\section{Introduction}

Biodiversity is a combination of the ecological complexes formed by organisms and their environments and the ecological processes associated with them, in- 
cluding animals, plants, microorganisms, the genes they possess, and the complex ecosystems they form with their habitats [1] [2]. On a larger scale, humans fall under the umbrella of biodiversity.

Since the 20th century, human society has faced five major development challenges: population, resources, environment, food, and energy, the root of which is the contradiction and conflict between humans and biodiversity. On the one hand, regional economic development depends on the physical resources provided by biodiversity for human beings, which inevitably have varying degrees of impact on biodiversity; on the other, the pursuit of effective biodiversity conservation is bound to affect regional economic development directly. The key to balancing this contradiction for human beings lies in fully recognizing the practical benefits of biodiversity conservation to achieve a synergistic and sustainable development of the economy and natural resources [3].

Governments and citizens have increased their awareness of biodiversity conservation, in which each social participant is working to protect biodiversity with the basic awareness that "lucid waters and lush mountains are invaluable assets". However, is there a direct relationship between biodiversity conservation and economic development? Can biodiversity conservation make a substantial contribution to economic development? Can this substantial contribution enhance social participants' perceptual awareness and, thus, their awareness of biodiversity conservation? These issues are keys to public participation in biodiversity conservation and sustainable development. Biodiversity conservation is a general concept that includes protecting the variety and variability of species in an area, the conservation of a species type and its habitat, and the preservation and management of a species [4] [5]. However, the conservation of key species in a biodiversity area can indicate the effectiveness and results of biodiversity conservation in that area to some extent.

This study investigated the Mount Huangshan Scenic Area located in a biodiversity conservation hotspot in China. Through field and questionnaire surveys, this study analyzed the current conservation of Huangshan Tibetan macaque ( $\mathrm{Ma}$ caca thibetana) - an endemic endangered species in China, the conservation awareness of residents and visitors and changes in local economic income. It provides inspiration and characteristic demonstration for building a synergistic model of endangered wildlife conservation, biodiversity maintenance, and sustainable regional economic development.

\section{Questionnaire Design}

A questionnaire was designed to investigate the current status of wildlife diversity conservation, conservation awareness, and changes in the economic income of residents. The questionnaire consisted of 26 questions, covering the respondents' personal background (questions $1-6$, Table 1), their interaction history with wild animals (questions $7-19$, Table 2), the impact of wildlife on the respondents' economic income (questions 20 - 21, Table 3), and their awareness of 
wildlife conservation (questions 22 - 26, Table 4).

\section{Questionnaire Survey}

The study investigated Fuxi Village located, at the southern foot of the Mount Huangshan Scenic Area. In addition to residents, this village is crowded with visitors from the provinces in East China who either visit the Huangshan Fuxi Wild Monkey Valley or enjoy agritainment activities [6] [7].

From August 12 to 16, 2020, under the guidance of professional teachers from the International Collaborative Research Center for Huangshan Biodiversity and

Table 1. Survey data on respondents' personal background.

\begin{tabular}{|c|c|c|}
\hline Indicator & Options & Percentage \\
\hline \multirow{3}{*}{ Gender } & Male & $48.33 \%$ \\
\hline & & \\
\hline & Female & $51.67 \%$ \\
\hline \multirow{5}{*}{ Age } & $18-30$ & $40.00 \%$ \\
\hline & $30-40$ & $21.67 \%$ \\
\hline & $40-50$ & $33.33 \%$ \\
\hline & $50-60$ & $3.33 \%$ \\
\hline & $>60$ & $1.67 \%$ \\
\hline \multirow{5}{*}{ Family size } & 3 & $43.33 \%$ \\
\hline & 4 & $20.00 \%$ \\
\hline & 5 & $21.67 \%$ \\
\hline & 6 & $13.33 \%$ \\
\hline & Others & $1.67 \%$ \\
\hline \multirow{3}{*}{ Source of income } & Traditional agriculture & $21.67 \%$ \\
\hline & Agritainment & $11.67 \%$ \\
\hline & Migrant work & $66.67 \%$ \\
\hline \multirow{5}{*}{ Education } & High School and below & $28.33 \%$ \\
\hline & Undergraduate & $45.00 \%$ \\
\hline & Postgraduate & $10.00 \%$ \\
\hline & Master & $5.00 \%$ \\
\hline & $\mathrm{PhD}$ & $11.67 \%$ \\
\hline \multirow{3}{*}{ Permanent residence } & Urban area & $68.33 \%$ \\
\hline & Rural area & $23.33 \%$ \\
\hline & Remote mountainous area & $8.33 \%$ \\
\hline
\end{tabular}


Table 2. Survey data on respondents' history of contact with wild animals.

\begin{tabular}{|c|c|c|}
\hline Indicator & Options & Percentage \\
\hline \multirow{2}{*}{ Have you ever seen a wild animal? } & Yes & $85.00 \%$ \\
\hline & No & $15.00 \%$ \\
\hline \multirow{5}{*}{ What wild animals have you seen? } & Monkey & $86.27 \%$ \\
\hline & Wild boar & $60.78 \%$ \\
\hline & Wolf & $13.73 \%$ \\
\hline & Tiger & $17.65 \%$ \\
\hline & Others & $15.69 \%$ \\
\hline \multirow{5}{*}{ The most familiar wild animal } & Monkey & $75.00 \%$ \\
\hline & Wild boar & $40.00 \%$ \\
\hline & Wolf & $6.67 \%$ \\
\hline & Tiger & $10.00 \%$ \\
\hline & Others & $6.67 \%$ \\
\hline \multirow{5}{*}{ Favorite wild animal } & Monkey & $68.33 \%$ \\
\hline & Wild boar & $10.00 \%$ \\
\hline & Tiger & $13.33 \%$ \\
\hline & Wolf & $11.67 \%$ \\
\hline & Others & $11.67 \%$ \\
\hline \multirow{4}{*}{ Ways to learn about wild animals } & Researcher & $28.33 \%$ \\
\hline & $\begin{array}{l}\text { Used to see when working in } \\
\text { the mountain and familiar }\end{array}$ & $33.33 \%$ \\
\hline & Heard of or occasionally seen & $53.33 \%$ \\
\hline & Not familiar & $10.00 \%$ \\
\hline \multirow{2}{*}{ Have you ever eaten a wild animal? } & Yes & $13.33 \%$ \\
\hline & No & $86.67 \%$ \\
\hline \multirow{2}{*}{ Have you ever rescued a wild animal? } & Yes & $33.33 \%$ \\
\hline & No & $66.67 \%$ \\
\hline \multirow{2}{*}{$\begin{array}{c}\text { Have you ever seen a } \\
\text { Huangshan Tibetan macaque? }\end{array}$} & Yes & $58.33 \%$ \\
\hline & No & $41.67 \%$ \\
\hline \multirow{4}{*}{$\begin{array}{l}\text { Have you ever been injured } \\
\text { by a wild monkey? }\end{array}$} & Been harassed & $11.67 \%$ \\
\hline & Been scratched & $5.00 \%$ \\
\hline & Been hospitalized & $0 \%$ \\
\hline & No & $83.33 \%$ \\
\hline \multirow{2}{*}{ Have you ever hunted a wild monkey? } & Yes & $0 \%$ \\
\hline & No & $100 \%$ \\
\hline \multirow{2}{*}{$\begin{array}{l}\text { Have the monkeys } \\
\text { ever destroyed the crops? }\end{array}$} & Yes & $28.33 \%$ \\
\hline & No & $71.67 \%$ \\
\hline \multirow{4}{*}{$\begin{array}{l}\text { What do you do if you see a } \\
\text { monkey destroying crops? }\end{array}$} & Repel & $88.24 \%$ \\
\hline & Hunt and kill & $0 \%$ \\
\hline & Do nothing & $11.76 \%$ \\
\hline & Others & $0 \%$ \\
\hline \multirow{2}{*}{$\begin{array}{l}\text { Have the monkeys ever } \\
\text { endangered your personal safety? }\end{array}$} & Yes & $10 \%$ \\
\hline & No & $90 \%$ \\
\hline
\end{tabular}


Table 3. Survey data on the impact of wildlife on respondents' economic income.

\begin{tabular}{ccc}
\hline Indicator & Options & Percentage \\
\hline & Increase & $38.33 \%$ \\
Impact of Tibetan macaques on the number of customers & No change & $58.33 \%$ \\
& Decrease & $3.33 \%$ \\
\hline Impact of Tibetan macaques on economic income & Increase & $25.00 \%$ \\
& No change & $71.67 \%$ \\
& Decrease & $3.33 \%$ \\
\hline
\end{tabular}

Table 4. Survey data on the awareness of wildlife conservation.

\begin{tabular}{|c|c|c|}
\hline Indicator & Options & Percentage \\
\hline \multirow{3}{*}{ Human-wildlife relationship } & Harmonious co-existence & $100 \%$ \\
\hline & Hostile & $0 \%$ \\
\hline & $\begin{array}{l}\text { Animals should be } \\
\text { used by humans }\end{array}$ & $0 \%$ \\
\hline \multirow{3}{*}{$\begin{array}{l}\text { How to promote the harmonious } \\
\text { co-existence of human and wildlife }\end{array}$} & More legislation & $56.67 \%$ \\
\hline & Protect animals by example & $88.33 \%$ \\
\hline & Others & $6.67 \%$ \\
\hline \multirow{3}{*}{$\begin{array}{l}\text { The extent to which Mount Huangshan is } \\
\text { dependent on environmental resources }\end{array}$} & More dependent & $50.00 \%$ \\
\hline & Not as dependent as before & $26.67 \%$ \\
\hline & Almost dependent & $23.33 \%$ \\
\hline \multirow{4}{*}{$\begin{array}{l}\text { Types of environmental } \\
\text { resources relied upon }\end{array}$} & Timber & $47.73 \%$ \\
\hline & Wild animals and plants & $54.55 \%$ \\
\hline & Home-farmed things & $70.45 \%$ \\
\hline & Others & $4.55 \%$ \\
\hline \multirow{4}{*}{$\begin{array}{l}\text { Awareness and action to } \\
\text { protect the environment }\end{array}$} & $\begin{array}{l}\text { I will always respond to the call to } \\
\text { protect the environment }\end{array}$ & $83.33 \%$ \\
\hline & Occasionally & $6.67 \%$ \\
\hline & $\begin{array}{l}\text { I have the awareness but not yet } \\
\text { implemented it }\end{array}$ & $10.00 \%$ \\
\hline & No & $0 \%$ \\
\hline
\end{tabular}

Tibetan Macaque Behavioral Ecology in Huangshan, Anhui Province, we conducted a survey and conservation action on endangered wildlife in Mount Huangshan, observing the local star animal, the Tibetan macaque, in the field (Figure 1). Additionally, we distributed 30 electronic questionnaires pertaining to the past and current status of endangered wildlife to local villagers and another 30 electronic questionnaires to tourists traveling in the area. A total of 60 valid questionnaires were received. Please visit the following URL:

(https://www.wjx.cn/mobile/statnew.aspx?activity=88098713\&reportid=\#1) to check the survey background statistics. 


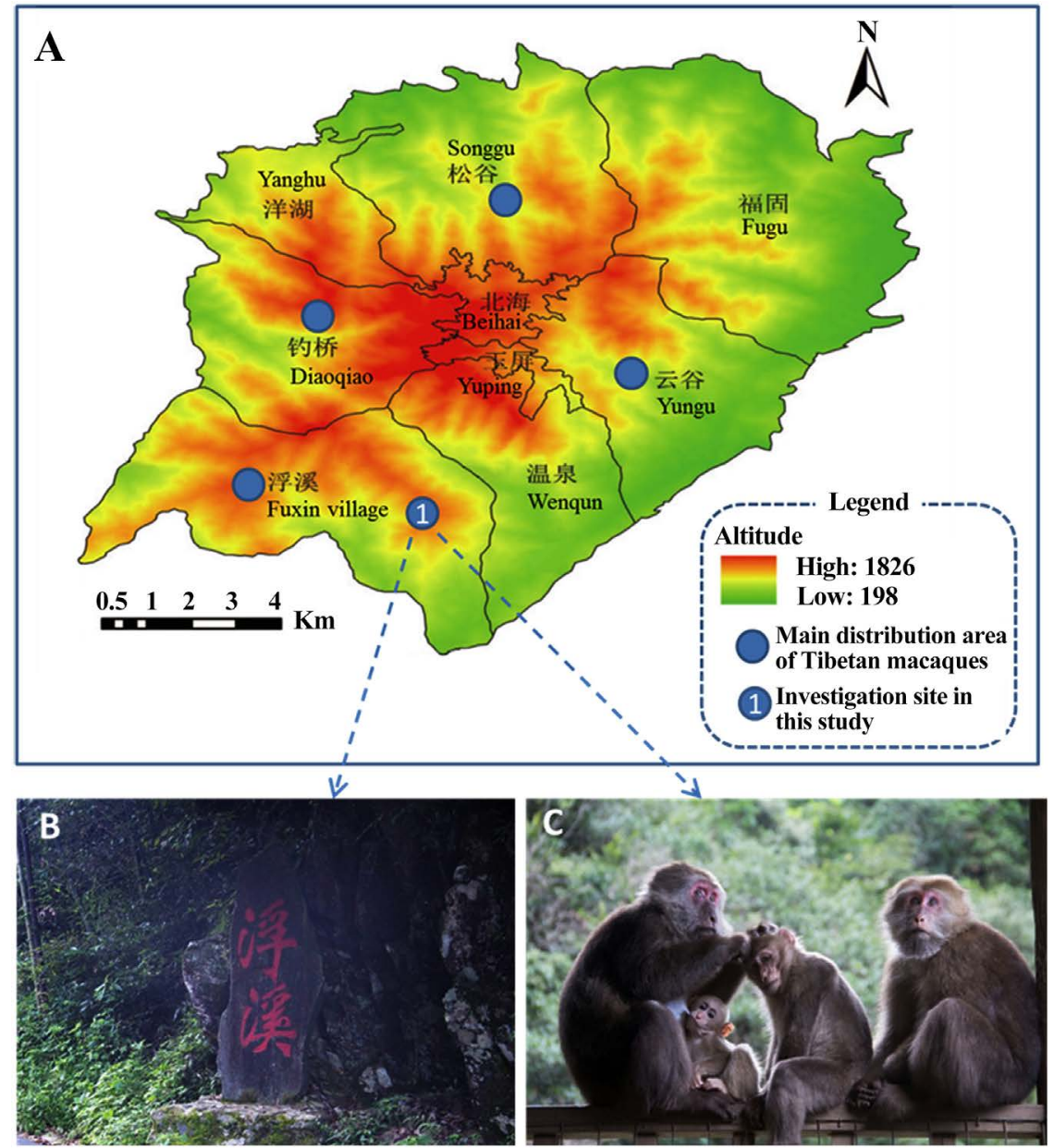

Figure 1. Distribution of Tibetan macaques in Mount Huangshan Scenic Area [6] [7]. (A) Huangshan Tibetan macaques are mainly distributed in Fuxi, Diaoqiao, Yungu, and Songgu management areas. (B) The investigation site (1) is located in Fuxi Village at the southern foot of the Mount Huangshan Scenic Area. (C) Tibetan macaques were closely observed at the observation site in Fuxi Village.

\section{Results and Discussion}

\subsection{Analysis of Respondents' Personal Background}

As shown in Table 1, the gender ratio of respondents was almost 50/50 between men and women. In terms of age distribution however, more than $95 \%$ of respondents were under 50 years old, likely related to the respondents' acceptance towards the use of electronic questionnaire. Older residents or visitors were not easily included in the survey due to their lack of proficiency using cell phones. The data on education and permanent residence largely reflected the distribution and composition of respondents who were split 50/50 between local residents (through household survey) and visitors to the Monkey Valley (through random survey). In addition, in terms of the source of income, $34 \%$ of the respondents relied on traditional agriculture and agritainment as their main source of income, while $66 \%$ worked outside their hometown. These figures also indicated the distribution and composition of the respondents. 


\subsection{Respondents' History of Interaction with Wild Animals}

To study wildlife conservation in the Monkey Valley, we further examined the experiences of local residents and tourists in contact with wild animals, as shown in Table 2. In the question "have you ever seen a Huangshan Tibetan macaque," we found that $41.67 \%$ of the respondents had not seen wild Huangshan Tibetan macaques, which was consistent with the fact that half of the respondents were tourists. Monkeys were chosen by the respondents (over 68\%) as the most seen, most familiar, and favorite wild animals, far ahead of others. This was consistent with the status of Huangshan Tibetan macaques as the star species in the Monkey Valley. This suggests that, in addition to local residents, tourists also have a high level of knowledge about the Tibetan macaques in the Monkey Valley, which may be one of the driving factors for these tourists to choose the Monkey Valley as a tourist destination. Furthermore, the conservation of biodiversity in scenic areas (e.g., the conservation of Huangshan Tibetan macaques) will be one of the effective means to promote local tourism development.

In terms of whether respondents had ever eaten wild animals, $13.3 \%$ said they had. Despite being a low percentage, wildlife consumption exists in a small group of people. However, a higher percentage of respondents (33.33\%) said they had rescued wild animals, further indicating that wildlife conservation awareness is spreading among a certain group of people. Moreover, the consciousness of Tibetan macaque conservation was further corroborated by the responses to questions regarding the damage that Tibetan macaques cause to cash crops and their danger to the respondents' personal safety. Specifically, $16.67 \%$ of the respondents indicated they had been harassed (scratched) by the Tibetan macaques, and $10 \%$ indicated that their personal safety had been endangered by the Tibetan macaques; $28.33 \%$ of the respondents said that the Tibetan macaques had damaged their crops, but $88.24 \%$ said they had only repelled the Tibetan macaques without hunting them. This shows that people in the Monkey Valley (including local residents and tourists) have a high conservation awareness of the Huangshan Tibetan macaque.

\subsection{Impact of Wildlife on Respondents' Economic Income}

We investigated the impact of the Huangshan Tibetan macaques as a representative of wildlife, on the income of residents (Table 3). As the local villagers of Fuxi Village in the Monkey Valley are engaged in the agritainment business, we used the change in the number of customers and the impact of economic income as the survey indicators. The survey showed that $38.33 \%$ of the respondents thought that the Tibetan macaques increased their number of customers and 25\% thought that the Tibetan macaques increased their economic income. As residents represent only half of the respondents, if tourists were excluded, more than $50 \%$ of the residents believed that the Tibetan macaques had increased the number of customers to their agritainment business and their economic income.

Biodiversity conservation sustainability relies on the gradual change in people's 
lifestyle. In this process, the level of socio-economic development determines the level of biodiversity conservation [8]. The most direct evidence is that the conservation of star species attracts more tourists, and that the increase in tourists allows residents to earn more. This change can be understood as a mechanism of payments for ecosystem services (EPS) in the form of market compensation [9]. Studies have shown that EPS in scenic areas provide additional funding for biodiversity conservation as well as continuity for cultural services in ecosystem services such as recreation, entertainment, and aesthetic enjoyment [10] [11]. Thus, our survey data support the idea that biodiversity conservation in scenic areas has a positive effect on local socio-economic development.

\subsection{Awareness of Wildlife Conservation}

According to the survey data on wildlife conservation awareness (Table 4), 100\% of the respondents believed that people and wildlife should live in harmony, $56.67 \%$ believed that the harmonious co-existence of human and wildlife should be promoted through additional legislation, $88.33 \%$ said they should lead by example to protect wildlife, and $83.33 \%$ said they had been following through on the call to protect the environment. In China, there are many important laws and policies regulating people to enhance their awareness of wildlife protection. For example, in Law of People's Republic of China on the Protection of Wildlife, Article 5 states that citizens of the People's Republic of China shall have the duty to protect wildlife resources and the right to inform the authorities of or file charges against acts of seizure or destruction of wildlife resources. The high proportion figures indicate that most people have been aware of the need and taken action to protect the ecological environment under the regulation of these laws and polices. In addition, more than $50 \%$ of the respondents believed that residents in Huangshan were more dependent on local resources such as timber, wild animals and plants, and cash crops than before. This illustrates that biodiversity conservation indirectly contributes to the efficient services by local ecosystems and allows humans to acquire better quality food and other services from biodiverse ecosystems [11].

\section{Conclusion}

This study conducted a field investigation of Fuxi Village in the Huangshan Monkey Valley-a scenic spot-and investigated the current status of wildlife diversity conservation, conservation awareness, and changes in the economic income of residents. It also focused on the impact of the Tibetan macaques, which served as a representative of wildlife, on resident's income. According to the survey data, biodiversity conservation in scenic areas has a positive impact on the level of local socio-economic development. The direct manifestation of this impact is that the conservation of the Tibetan macaques attracts more tourists and that the increase in tourists allows residents to earn more. This can be understood as a mechanism of payments for EPS in the form of market compensation. The EPS 
provides additional funding for biodiversity conservation as well as continuity for cultural services in ecosystem services such as recreation, entertainment, and aesthetic enjoyment. The survey data further illustrate that biodiversity conservation indirectly contributes to the efficient services by local ecosystems and allows humans to acquire better quality food and other services from biodiverse ecosystems. In conclusion, our survey data support the idea that biodiversity conservation in scenic areas has a positive effect on local socio-economic development. This preliminary study provides a basis for other researchers or policymakers to establish a virtuous development model of biodiversity conservation and regional socio-economic development.

\section{Acknowledgements}

As high school students, we have a strong interest in nature, biodiversity, and the conservation of endangered species, among other topics. We have had the opportunity to follow the research experts of Tibetan macaques in Mount Huangshan, China, to Fuxi Village in the Huangshan Monkey Valley for a field survey. We had direct contact with the Tibetan macaques at the Monkey Valley. Under the guidance of our teachers, we were able to gain a preliminary understanding of the relationship between endangered wildlife conservation and local economic development through a reasonable questionnaire design and a case study of the Huangshan Tibetan macaques and Fuxi Village. This survey on the Huangshan Tibetan macaques and endangered wildlife conservation helped us realize the importance of maintaining the Earth's biodiversity, which is the premise and destination of the synergistic and sustainable development of human society and the Earth's ecosystem.

\section{Conflicts of Interest}

The authors declare no conflicts of interest regarding the publication of this paper.

\section{References}

[1] Jiang, Z., Ma, K. and Han, X. (1997) Conservation Biology. Zhejiang Science and Technology Press, Hangzhou.

[2] Xu, F., Peng, R. and Yang, X. (2012) Analysis on the Effects of Regional Socio-economic Development on the Biodiversity. Journal of Anhui Agriculture Science, 40, 3842-3844.

[3] Wikipedia, The Free Encyclopedia (2021, June 1) Biodiversity. https://simple.wikipedia.org/w/index.php?title=Biodiversity\&oldid=7591266

[4] Guo, H., Li, H. and Dao, Z. (2000) Dynamism of Socio-Economy and Biodiversity Interaction: a Case from Gaoligong Mountains. Acta Botanica Yunnanica, 22, 42-51.

[5] Huang, Z., Li, R., Mai, Q., Peng, Z., Chen, H. and Jiang J. (2005) The Relationship between Agrobidiversity and Socially Economic Development in Hainan and Its Protective Strategy. Chinese Journal of Tropical Agriculture, 25, 25-28.

[6] Yang, Y., Wang, F., Li, X. and Cheng, W. (2006) Theory and Practice of Biodiversity 
Protection in Scenic Spots: An Example of Bio-Diversity Protection in Mount Huangshan. Sichuan Environment, 25, 39-42.

[7] Gao, Z., Xu, J., Wang, S. and Tian, H. (2015) Research on Regional Risk Zonation of Mountain Torrent Disasters in Huangshan Scenic Area. Torrential Rain and Disasters, 34, 281-285.

[8] Jiao, X. (2002) On the Relationship between Social and Economic Development and Biodiversity in Gaoligong Mountain. Chinese Wildlife, 6, 32-34.

[9] Uta, S., Davide, M., Angelo, M. and Margherita, P. (2018) Positive Effects of Payments for Ecosystem Services on Biodiversity and Socio-economic Development: Examples from Natura 2000 Sites in Italy. Ecosystem Services, 34, 96-105.

https://doi.org/10.1016/j.ecoser.2018.10.006

[10] Pan, X., Xu, L., Yang, Z. and Yu, B. (2017) Payments for Ecosystem Services in China: Policy, Practice, and Progress. Journal of Cleaner Production, 158, 200-208. https://doi.org/10.1016/j.jclepro.2017.04.127

[11] Liu, L., Liu, H., Ren, J., Bian Z. and Ding, S. (2017) Research Progress on the Mechanism of Ecosystem Services Generation. Chinese Journal of Applied Ecology, 28, 2731 2738 . 